\title{
NANOPARTICLE BASED BIOSENSOR FOR PENICILLIN QUANTIFICATION IN PHARMACEUTICALS
}

\author{
EMINE KARAKUS ${ }^{*}$, CISEM TURAN $^{1}$ \\ 1,1*Department of Chemistry, Faculty of Arts and Sciences, Yıldız Technical University: Esenler, 34290, ISTANBUL, Turkey \\ Email: eminekaraku@gmail.com
}

Received: 29 Sep 2019, Revised and Accepted: 16 Nov 2019

\begin{abstract}
Objective: The objective of this study was to develop a new biosensor system based on nanoparticle to determine penicillin in pharmaceuticals.

Methods: The characterization and optimization of the potentiometric penicillin biosensor (PB) were prepared by using synthesized surfacedependent and surface-independent $\mathrm{ZnO}$ nanoparticles named $\mathrm{ZnO}$ nanorods and chitosan were carried out. It was preferred ZnO nanorod because of its electrical, optical, physical and photocatalyst properties, biocompatibility and non-toxicity in the construction of the penicillin biosensor.
\end{abstract}

Results: The operating range was obtained as $10^{-1}-10^{-3} \mathrm{M}$, the optimum buffer concentration was $10 \mathrm{mmol}$, optimum pH was 7.4 and the optimum temperature was $25^{\circ} \mathrm{C}$ for the PB. The PB has advantages in terms of short response time, long enough shelf life, cheap, and easy elaborate.

Conclusion: Whether the biosensor can be used to determine penicillin and accurately measure penicillin, the amount of penicillin in a commercial pharmaceutical preparation named Alfoxil was successfully made by using our prepared penicillin biosensor.

Keywords: Penicillin, Zinc oxide nanorod, Biosensor, Potentiometric, Chitosan

(C) 2020 The Authors. Published by Innovare Academic Sciences Pvt Ltd. This is an open-access article under the CC BY license (http://creativecommons.org/licenses/by/4.0/) DOI: http://dx.doi.org/10.22159/ijap.2020v12i1.35906. Journal homepage: https://innovareacademics.in/journals/index.php/ijap

\section{INTRODUCTION}

Penicillin concentration is important in terms of biochemical and physiological reactions in the human body. In order to determine antibiotics such as penicillin, there are different techniques such as microbiotic, chromotographic, spectrophotometric, fluorimetric and electrochemical. Among these, electrochemical based penicillin biosensors are widely studied because the cost of preparation is low, the selectivity is high and the applicability is simple [1]. The determination of different kinds of penicillin are very important in medicine, pharmaceutical production, environmental monitoring and biochemical process control. Although many potentiometric enzyme biosensors have been developed for the detection of penicillin G, mainly for the analysis of fermentation broths, where it requires the determination of relatively high concentrations of penicillin. A rapid and inexpensive analysis method and biochemical sensors to detect small amounts of penicillin for many fields of application (e. g. drug control-analysis of antibiotic tablets, capsules and injectables, clinical laboratories, food control, etc.) are needed. Such sensors should possess both high stability in the long-term as well as a low detection limit [2].

Nanosized materials are of special interest due to novel electrical, mechanical, chemical and optical properties and increasing surface area and having higher efficiency that are introduced by surface and quantum confinement effects $[1,3,4]$. Zinc oxide $(\mathrm{ZnO})$ is one of the most important semiconductor materials because of the availability of a variety of nanostructures such as nanowires, nanorods, nanotubes etc. Beside $\mathrm{ZnO}$ nanorods have numerous applications in bioelectronics and nanoelectronics fields, they are frequently used for biosensing applications due to special properties such as high surface area to volume ratios, great chemical stability, biocompatibility, easy growing and simple fabrication [1]. Because $\mathrm{ZnO}$ nanorods have also nontoxic and fast electron communication, they can be used to construct electrochemical biosensors in combination with immobilized enzymes [5-10].

In the literature, the majority of penicillin biosensors are amperometric. Potentiometric penicillin biosensor prepared by using penicillinase, both zinc oxide nanorod and chitosan hasn't been found. In this study, the preparation and analytical characterization of the penicillin biosensor (PB) were made by using ZnO nanorods and chitosan.

\section{MATERIALS AND METHODS}

\section{Materials and reagents}

Hexamethylenetetramine and zinc nitrate were used for the synthesis of nanorods, penicillinase (1150.39 Units/g) from Bacillus cereus, D-(+)-glucose monohydrate, chitosan, L-ascorbic acid, uric acid, zinc nitrate tetrahydrate sodium phosphate dibasic and monobasic sodium phosphate used in the study were purchased from Sigma Chem. Co. (St. Louis, MO). All reagents were used without purification in all stages of the study. Alfoxil $500 \mathrm{mg}$ tablets of Actavi firm was purchased from a local pharmacy in İstanbul.

Potential measurements of the solutions were done with ORION 4 Star Benchtop pH-ion meter. Sartorius PB-11 pH meter was used for pH measurements. A double-contact silver-silver chloride electrode was used as the reference electrode (Orion 90-02). These electrode filler solutions were filled with ORION 900002 and 900003 catalog numbered solutions. Brand micropipettes were used for solution additions. Bidestile water used during all of the studies was obtained by using PURELAB Classic water purification device. The prepared zinc oxide nanorodes were visualized using EVO LS-10 Zeissbranded Scanning Electron Microscopy (SEM).

\section{Preparation on zinc oxide nanorods}

Zinc oxide nanorodes can be bound to a surface (silver, gold wire or sheet, etc.) or can be formed by a hydrothermal method independent of the surface. In this study, ZnO nanorod production was performed by both methods.

For surface-dependent $\mathrm{ZnO}$ nanorod synthesis, the silver wire was washed in acetone, ethanol and bidistilled water and then immersed in a solution of $95 \mathrm{ml}$ of $0.025 \mathrm{M} \mathrm{Zn}\left(\mathrm{NO}_{3}\right)_{2}$ and $0.025 \mathrm{M}$ hexamethylenetetramine (HMT) in $25 \mathrm{ml}$ volumes and immersed for about $2-4 \mathrm{~h}$ to evaporate the solution. The appearance of a white layer on the silver wire surface indicates that $\mathrm{ZnO}$ nanorodes are formed. The coated wire was washed with distilled water and allowed to dry for $5 \mathrm{~min}$ at room temperature.

\section{Preparation of penicillin biosensor (PB)}

Penicillinase enzyme was immobilized onto the zinc oxide nanorods prepared by using silver wire. We also used chitosan to make penicillinase better immobilized onto nanorod surface. The 
penicillin biosensor was prepared using both surface-dependent and surface-independent $\mathrm{ZnO}$ nanorods.

Surface-dependent $\mathrm{ZnO}$ nanorod was allowed to stand for $5 \mathrm{~min}$ in $0.1 \mathrm{M}$ phosphate buffer ( $\mathrm{pH} 7.4$ ) to form hydrophilic surfaces on the nanorod. Nanorod was immersed in a solution containing $1 \mathrm{ml}$ chitosan/0.5 ml penicillinase enzyme (pH 7.4) for $30 \mathrm{~min}$. Enzyme electrode was incubated in the solution obtained by mixing $2 \mathrm{mg}$ of surface-independent $\mathrm{ZnO}$ nanorods and $1 \mathrm{ml}$ of chitosan solution during $15 \mathrm{~min}$. In the result of this, it was provided to stand and coated the surface-independent $\mathrm{ZnO}$ nanorod particles to the electrode with chitosan. In this way, the penicillinase enzyme was better immobilized to the electrode surface and the conductivity of PB our prepared was increased. The prepared penicillin biosensor was dried at $+4{ }^{\circ} \mathrm{C}$ for $15 \mathrm{~min}$. The dried PB was incubated in $1 \mathrm{ml}$ penicillinase enzyme solution ( $\mathrm{pH}:$ 7.4) for 1 hour. Thus, the enzyme was immobilized electrostatically to the nanorod surface. The prepared penicillin biosensor was kept at $+4{ }^{\circ} \mathrm{C}$ for $15 \mathrm{~min}$ to dry.

Preparation of penicillin biosensor (PB) is shown in fig. 1

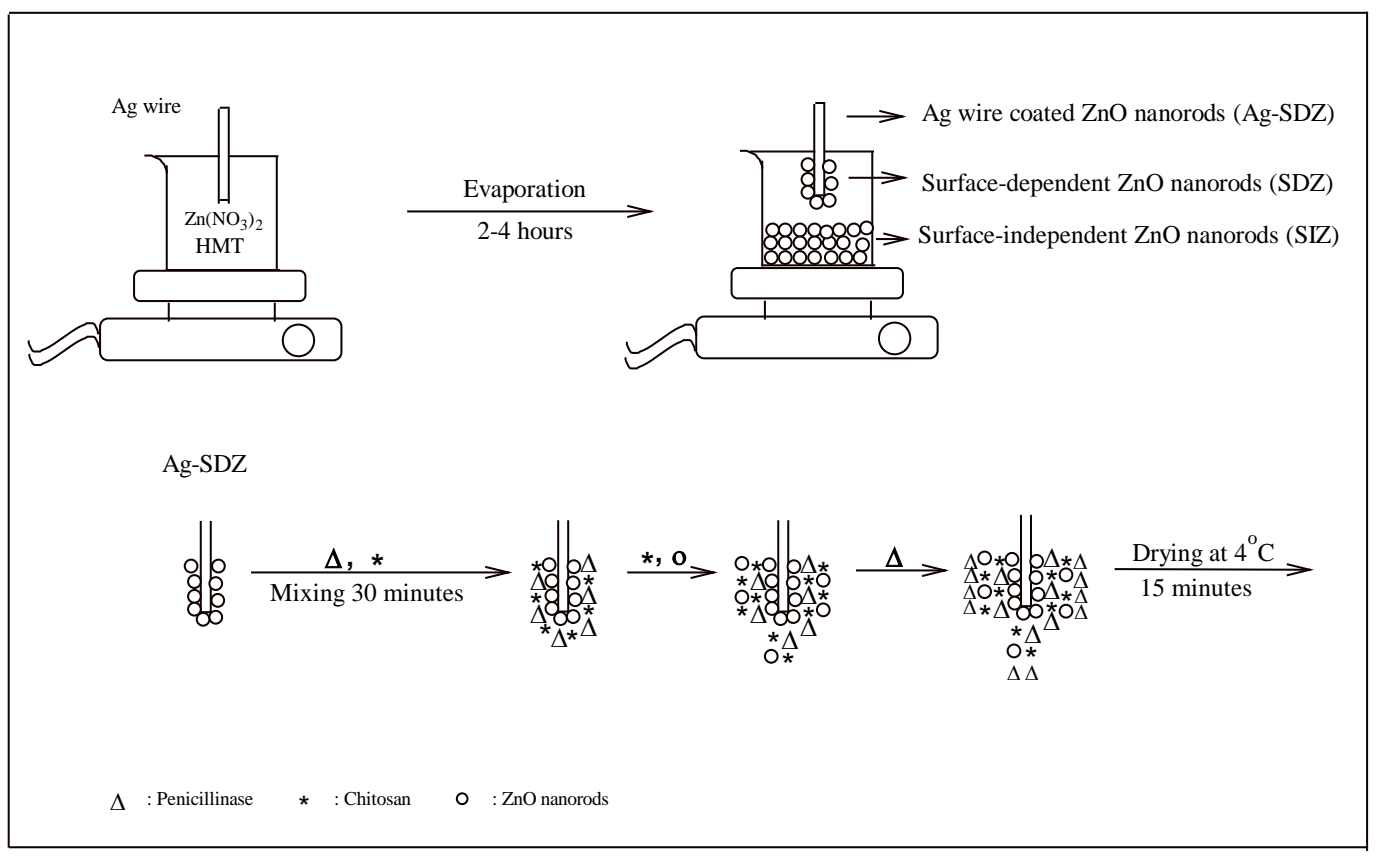

Fig. 1: Preparation of penicillin biosensor (PB)

\section{Determination of working range and slope of penicillin biosensor}

To investigate the analytical properties of the prepared penicillin biosensor, the following electrochemical cells were generated and the temperature was set at $25.0 \pm 1.0^{\circ} \mathrm{C}$.

Reference electrode/test solution/chitosan/penicillinase/ZnO nanorod coated silver wire/Ag; $\mathrm{AgCl}$

The concentration of penicillin solutions in the electrochemical cell was varied from $1.0 \times 10^{-1}$ to $1.0 \times 10^{-7} \mathrm{M}$. The $\mathrm{pH}$ of the penicillin solutions was adjusted to the optimum $\mathrm{pH}$ by phosphate buffer and the individual cell potentials were recorded for the prepared electrodes. The potential values $(\mathrm{mV})$ against $\log$ [penicillin] for each electrode were plotted and the operating range and slope of the biosensors were determined.

\section{Determination of factors affecting the performance of penicillin biosensor}

On the response of the prepared penicillin biosensors, the effect of the buffer concentration, $\mathrm{pH}$, temperature, mixing speed, repeatability, response time, interference effect was determined and the shelf life was determined.

\section{Reproducibility of penicillin biosensors}

Repeatability is an important parameter for biosensors. The activity, stability and purity of the enzyme preparation are important in obtaining reproducible results with the enzyme biosensor prepared. However, it is possible to encounter very large differences in the expected qualities in terms of the biosensor preparation stages and working environment. The simplification of reproducibility with a prepared biosensor carry out repeat measurements in the same sample, calculate the slopes from the obtained values and converting each slope value to a percentage.

On the same day, $\mathrm{mV}$ measurements were made in penicillin calibration solutions ( 10 series between $10^{-5} \mathrm{M}$ and $10^{-7} \mathrm{M}$ ) with the same biosensor prepared once every $15 \mathrm{~min}$ and calibration graphs were drawn and the slope of each graph was determined. The biggest slope values were considered as 100 , and the other slope values were calculated according to it.

\section{RESULTS AND DISCUSSION}

The SEM images of the resulting nanorodes were obtained to ensure that the coating was best achieved (fig. 2).

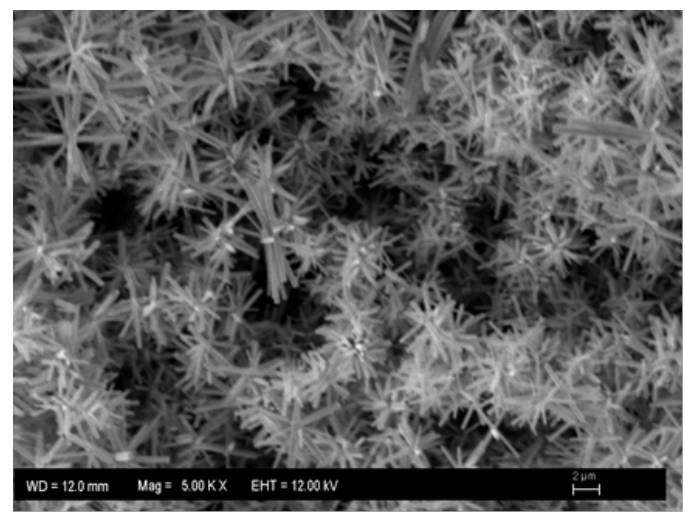

Fig. 2: SEM image of ZnO nanorods 
For surface-independent $\mathrm{ZnO}$ nanorod synthesis, the solution consisting of mixing $0.025 \mathrm{M} \mathrm{Zn}\left(\mathrm{NO}_{3}\right)_{2}$ and $0.025 \mathrm{M}$ hexamethylenetetramine (HMT) in $25 \mathrm{ml}$ volumes in a beaker was left completely evaporated by standing at $95{ }^{\circ} \mathrm{C}$ during $2-4 \mathrm{~h}$. A white-colored layer formed at the bottom of beaker shows that $\mathrm{ZnO}$ nanorodes are formed.

\section{The calibration graph of penicillin biosensor}

In this study, the penicillin biosensor (PB) was prepared by immobilizing the penicillinase enzyme onto the surface-dependent<smiles>[R]C(=O)NC1C(=O)C23C(=O)C(C(=O)O)C1C2SC3(C)C</smiles>

Penicillin and surface-independent $\mathrm{ZnO}$ nanorod and chitosan surface. After biochemical characterization of the prepared penicillin biosensor, the amount of penicillin in the pharmaceutical preparation named Alfoxil was determined successfully.

The formation of penicilloat and hydrogen ions after the reaction of penicillinase enzyme with penicillin cause to change in the electrode potential in proportion to penicillin amount in the medium.

After the potential values as $\mathrm{mV}$ due to the hydrogen ion formed as a result of the enzymatic reaction was plotted against the penicillin concentration in the measurements made with $\mathrm{PB}$, the slope values of the graph were determined.

The calibration graph of penicillin biosensor is given in fig. 3 .

The working range and slope value of PB were $1.0 \times 10^{-2}-1.0 \times 10^{-5} \mathrm{M}$ and $24.8 \mathrm{mV} / \mathrm{p}$ [penicillin] from fig. 1, respectively. Ibupoto et al. (2011) were determined the working range of their penicillin biosensor prepared by using $\mathrm{Ag} / \mathrm{AgCl}$ reference electrode between $1.0 \times 10^{-1}-1.0 \times 10$ ${ }^{4} \mathrm{M}$ at room temperature. ${ }^{1)}$ In another study, the working range of electrochemical penicillin $\mathrm{G}$ immunosensor developed at the trans level

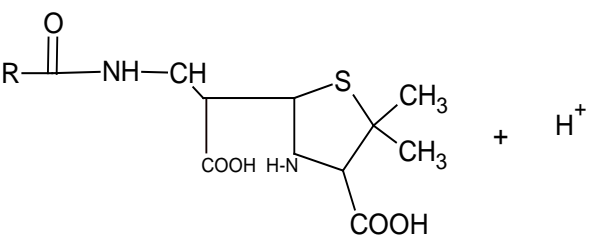

Penicilloic acid

using gold nanoparticles was determined as $3.34 \times 10^{-3} \mathrm{M}-1 \times 10^{3} \mathrm{M}$ [11] Our prepared PB has the advantage that it allows the determination of penicillin in a wider range and lower concentration.

\section{Effect of buffer concentration}

In order to examine the effect of buffer concentration on the performance of penicillin biosensor, calibration measurements were made by measuring the potential of the biosensor in penicillin solutions ( $\mathrm{pH}$ 7.4) prepared by using phosphate buffer in 5 different penicillin concentrations $(5,7,10,15$ and $20 \mathrm{mmol})$ and graphed the slopes against buffer concentration after determined the slopes for each penicillin solution (fig. 4).

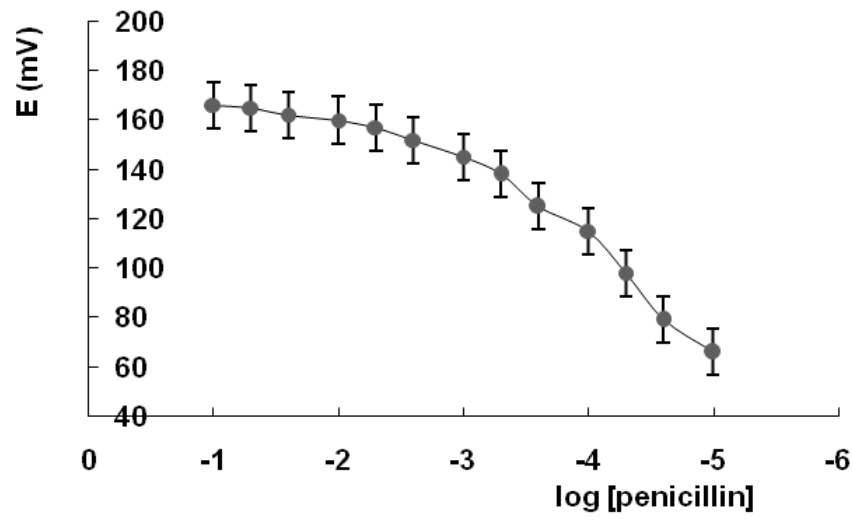

Fig. 3: The calibration graph of $\mathrm{PB}$, the experiments were triplicated in each step

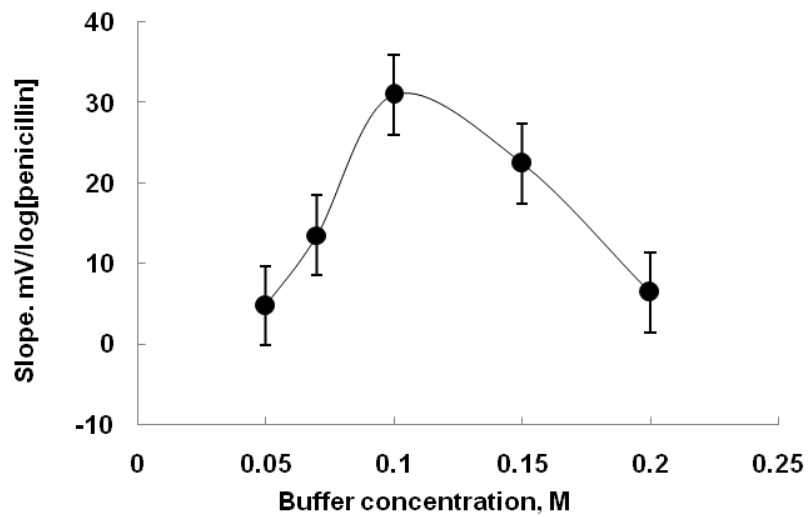

Fig. 4: Change of the slope of PB with buffer concentration, the experiments were triplicated in each step 
Liu et al. (1998) carried out potential measurements with their prepared the amperometric penicillin biosensor at 5, 10, 20 and 40 mmol penicillin solutions mmol in phosphate buffer and determined the optimum buffer concentration of the biosensor found as 20 [12]. In this study, the optimum buffer concentration was determined as $10 \mathrm{mmol}$ by using phosphate buffer. Increased buffer concentration resulted in a decrease in the biosensor slope (fig. 4).

\section{Effect of $\mathbf{p H}$}

To examine the effect of $\mathrm{pH}$ on our prepared penicillin biosensor's performance, the potential measurements were carried out in penicillin solutions at 7 different $\mathrm{pH}(6.4 ; 6.6 ; 7.0 ; 7.2 ; 7.4 ; 7.6$ and 7.8). The slope values were plotted against $\mathrm{pH}$ after determined for each penicillin solution (fig. 5).

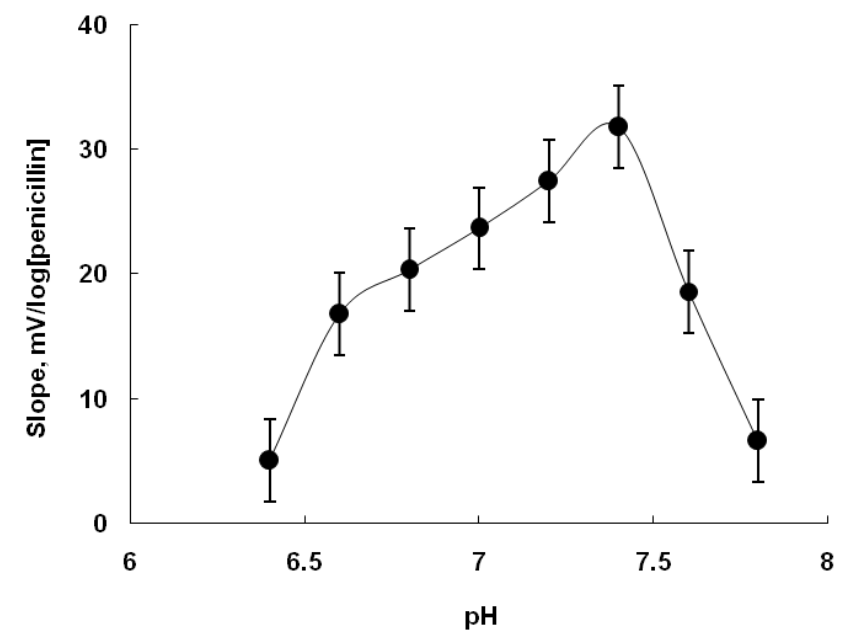

Fig. 5: Change of the slope of $\mathrm{PB}$ with $\mathrm{pH}$, the experiments were triplicated in each step

The optimum $\mathrm{pH}$ of $\mathrm{BP}$ was found as 7.4. As seen in fig. 5, the slope of the $\mathrm{BP}$ our prepared has reached the maximum value at $\mathrm{pH} 7.4$ and has decreased below after 7.4. Liu et al. (1998) optimum $\mathrm{pH}$ of their prepared penicillin biosensor was determined as 7 at 3 different $\mathrm{pH}$ values as 6, 7, 8 and $20 \mathrm{mmol}$ phosphate buffer [12]. Thust et al. (1996) compared the $\mathrm{pH}$ values between 3 and 10 in their potentiometric penicillin biosensor. The optimum $\mathrm{pH}$ value was determined as 7 in this study [13]. In this study, the optimum $\mathrm{pH}$ was determined as 7.4.

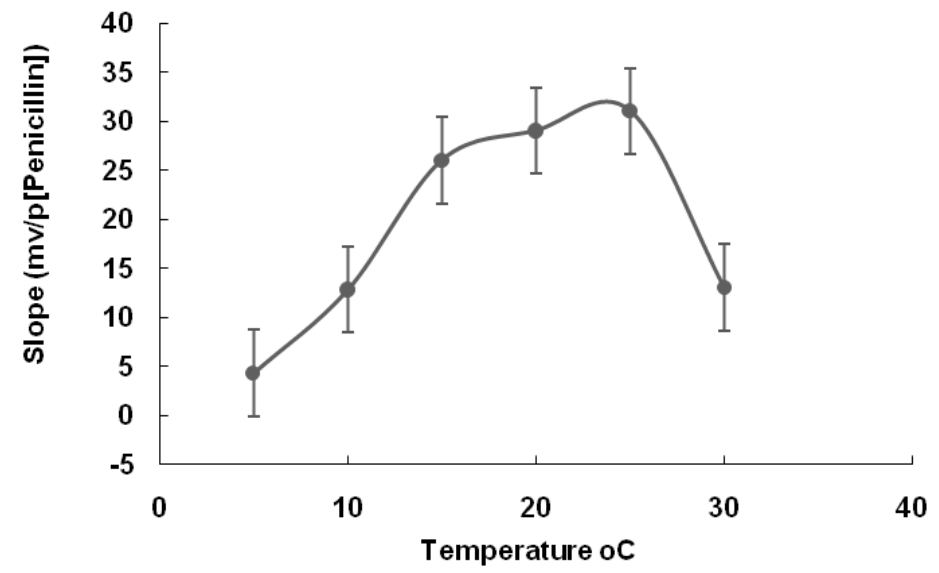

Fig. 6: Change of the slope of PB with temperature, the experiments were triplicated in each step

\section{Effect of temperature}

At 5 different temperatures $\left(5,10,20,25\right.$ and $\left.30{ }^{\circ} \mathrm{C}\right)$, the temperature effect of our prepared $\mathrm{PB}$ was determined by measuring the potential measurements at its optimum $\mathrm{pH}$ and optimum buffer concentration. After determined slope values for each temperature, it was plotted against temperature (fig. 6).

As can be seen from fig. 4 , the BP our prepared did not respond at a temperature below $10^{\circ} \mathrm{C}$ and above $25^{\circ} \mathrm{C}$, and showed maximum performance at $25{ }^{\circ} \mathrm{C}$. Ibupoto et al. (2011), with the penicillin biosensor their prepared between $20^{\circ} \mathrm{C}$ and $80^{\circ} \mathrm{C}$ in their work, the maximum performance was seen at $50{ }^{\circ} \mathrm{C}$, but the biosensor didn't show the stability at this temperature as that of $25{ }^{\circ} \mathrm{C}$ temperature [1]. Therefore, the studies related to penicillin biosensors in the literature are generally studied at $20-25{ }^{\circ} \mathrm{C}$ temperature ranges.

\section{Interference effect and mixing speed}

In order to determine the effect of some substances on the performance of the prepared $\mathrm{ZnO}$ nanorod based $\mathrm{PB}$, calibration solutions ( $\mathrm{pH}:$ 7.4) were prepared in three different concentrations using the $10-6 \mathrm{M}$ penicillin calibration solution $(\mathrm{pH} 7.4)$. The $\mathrm{mV}$ measurements were made separately in an only penicillincontaining calibration solution $(\mathrm{pH}$ 7.4) and penicillin and interference substance-containing calibration solution ( $\mathrm{pH}$ 7.4) The results are shown in table 1. 
Table 1: Interference rates of certain species in PB our prepared

\begin{tabular}{llll}
\hline Interference & Interference (\%) at different interference concentration $\pm s^{*}$ & \\
\cline { 2 - 4 } & $\mathbf{1 0}^{-\mathbf{2}} \mathbf{M}$ & $\mathbf{1 0}^{-\mathbf{3}} \mathbf{M}$ & $\mathbf{1 0}^{-\mathbf{4}} \mathbf{M}$ \\
\hline Cephalosporine & 0.0 & 0.0 & 0.0 \\
D-glucose & 0.0 & 0.0 & 0.0 \\
L-glucose & 0.0 & 0.0 & 0.0 \\
L-ascorbic acid & 0.0 & 0.0 & 0.0 \\
Sucrose & 0.0 & 0.0 & 0.0 \\
Lactose & 0.0 & 0.0 & 0.0 \\
Glycine & 0.0 & 0.0 & 0.0 \\
Uric acid & 0.0 & $10.4 \pm 0.10$ & 0.0 \\
NaCl & 0.0 & $12.2 \pm 0.12$ & $8.6 \pm 0.14$ \\
KCl & 0.0 & 0.0 & 0.0 \\
\hline
\end{tabular}

The experiments were triplicated in each step, *s: Standard deviation

$\mathrm{Na}^{+1}, \mathrm{~K}^{+1}$, D-glucose, L-glucose, ascorbic acid, uric acid, urea, sucrose, lactose, glycine, penicilonic acid and sepholosporin were not any interference effect on the work of the penicillin biosensor. ${ }^{1)}$ In this study, the substance on table 1 didn't show any interference effect on the our prepared PB except $10^{-3} \mathrm{M}$ of uric acid and $10^{-3} \mathrm{M}$ and 10 ${ }^{4} \mathrm{M}$ of $\mathrm{NaCl}$. The interference effect of the certain concentration of uric acid and $\mathrm{NaCl}$ were so low (table 1 ).

To determine the mixing speed effect on the PB, the magnetic stirrer was allowed to stabilize the potential of the penicillin solutions by adjusting the speed to three different speeds of 300, 400 and 500 rpm. Compared to the measurements taken, it was seen that increasing the mixing speed did not have any effect on the potential of the biosensor.

\section{Response time, shelf life and repeatability}

The response time is the time from the moment the biosensor contacted the medium to be analyzed to the moment the reading of the result from the measurement device. Response time for biosensors up to $5 \mathrm{~min}$ is considered appropriate, while $10 \mathrm{~min}$ is seen as a long period. The response time for the biosensor is very important, an ideal biosensor should be able to give results in a short time [13].

The $\mathrm{mV}$ measurements were carried out with our prepared PB in the penicillin solutions at the different concentrations at optimum conditions of it. In this measurements by immersing working and $\mathrm{Ag} / \mathrm{AgCl}$ reference electrode, the time taken to stabilize their potential was recorded. The response time of our prepared PB was less than 1 minute. It has relatively short response time.

The biosensor was stored at in $+4{ }^{\circ} \mathrm{C}$. The slope values were determined to carry out $\mathrm{mV}$ measurements in penicillin solutions by taking twice a week In order to determine the shelf life of our prepared PB. At the end of fifteen days, both biosensors did not respond. The analytical responses of PB our prepared were found to be good and could not be stored for a long time.

In order to determine the reproducibility of $\mathrm{PB}$ our prepared, $\mathrm{mV}$ readings were made on 3 serial penicillin calibration solutions on the same day prepared with the same biosensor and the slopes were determined by drawing a calibration graph for each measurement. The largest slope value was $100 \%$ and the other slope values were calculated accordingly and the second measurement of the biosensor decreased by up to $70 \%$.
The low shelf life and reproducibility of the penicillin biosensor can made it a biosensor that can be used for the determination of singleuse penicillin when applied on a flexible surface. on the biosensor preparation. A lot of silver wires to prepare the biosensor can be coated with zinc oxide nanorods and chitosan simultaneously. When the wires are covered, the biosensor preparation takes $1.45 \mathrm{~h}$. After working with biosensors, that nanorod-coated electrodes can be sanded and used again in biosensor preparation to reduce the cost of biosensor preparation. Although the shelf life and reproducibility of the biosensor our developed is low, it has some advantages such as easy, practical and low in cost to prepare the biosensor.

Determination of enzyme kinetic parameters ( Km and Vmax values)

The enzyme kinetic parameters ( $\mathrm{Km}$ and Vmax values) determination for biochemical reactions are very important in terms of providing about operation of enzymes and enzyme-based biosensors. Vmax, is the maximum speed that enzymatic catalysis can reach. The enzyme regions reach the maximum speed (Vmax) when the substrate is in full saturation. Michaelis-Menten constant, $\mathrm{Km}$, is the amount of substrate needed to reach half of the maximum speed value and is specific to the enzyme. The value reflects the interest of the enzyme to the substrate. An enzyme with low $\mathrm{Km}$ shows a high affinity for its substrate [13]. We have graphed the Lineweaver-Burk graph of the penicillinase enzyme immobilized in $\mathrm{PB}$ by using the potential change against penicillin concentration (1/[penicillin immobilized in $\mathrm{PB}]-1 / \Delta \mathrm{mV}$ graph) in order to find the $\mathrm{Km}$ and Vmax constants from the data in the Lineweaver-Burk graph. The $\mathrm{Km}$ value of penicillinase enzyme in PB from; the Lineweaver-Burk graph was found as $0.84 \mathrm{mmol}$ and Vmax $135.1 \mathrm{mV} / \mathrm{min}$, respectively. The penicillin enzyme in the amperometric penicillin biosensor prepared by using gold electrodes was found the $\mathrm{Km}$ value of $0.094 \mathrm{mmol}$ [14]. In our measurements with our developed $\mathrm{PB}$, this value was found to be $0.84 \mathrm{mmol}$.

Determination of penicillin in commercial pharmaceutical formulation

We investigated whether penicillin biosensors should be used in pharmaceutical samples. The amount of penicillin in commercially purchased Alfoxil $500 \mathrm{mg}$ tablets of Actavi firm was determined by using the standard addition method (table 2).

Table 2: Determination of penicillin in commercial pharmaceutical formulation

\begin{tabular}{ll}
\hline Reference value in $\mathbf{5 0 0} \mathbf{~ m g}$ of Alfoxyl powder $(\boldsymbol{\mu g} / \mathbf{2 0 0} \boldsymbol{\mu l}) \pm \mathbf{s}^{*}$ & Penicillin biosensor $(\boldsymbol{\mu g} / \mathbf{2 0 0} \boldsymbol{\mu l}) \pm \mathbf{s}^{*}$ \\
\hline $25.1 \pm 0.1$ & $25.4 \pm 0.2$ \\
\hline
\end{tabular}

The experiments were triplicated in each step, *s: Standard deviation

As can be seen in table 2, the amount of pensilin obtained from our prepared PB and the amount of pensilin in Alfoxil $500 \mathrm{mg}$ are close to each other. This situation shows that the penicillin assay is successfully performed with our sensor.

\section{CONCLUSION}

In this study, we developed a biosensor for penicillin assay in commercial pharmaceutical preparate by using $\mathrm{ZnO}$ nanorods and 
chitosan. We proposed a novel strategy for penicillin detection without the important interference effect of the other species with our prepared biosensor.

\section{ACKNOWLEDGMENT}

This study was supported by Yildiz Technical University Scientific Research Project Coordination, Turkey.

\section{AUTHORS CONTRIBUTIONS}

Experimental design, execution, data generation, support to draft manuscript design, data interpretation and corrections were done by Emine Karakuş and Çisem Turan. The design, guidance for work and manuscript review was done by Emine Karakuş. All authors were revised and review the manuscript.

\section{CONFLICT OF INTERESTS}

\section{Declared none}

\section{REFERENCES}

1. Ibupoto ZH, Usman Ali SM, Khun K, Chey CO, Nur O, Willander $\mathrm{M}$. ZnO nanorods based enzymatic biosensor for selective determination of penicillin. Biosens 2011;1:153-63.

2. Wu Y, Tang L, Huang L, Han Z, Wang J, Pan H. A low detection limit penicillin biosensor based on single garphene nanosheets preadsorbed with hematein/ionic liquids/penicillinase. Mat Sci Eng C 2014;39:92-9.

3. Mondol R, Paul S, Ray S, Maiti S. Polymerıc nanocarrıers: a promising research avenue for the delivery of anti-hiv drugs. Int J Appl Pharm 2010;2:1-5.
4. Karliana D, Anwar E, Bahtiar A. Formulation and evaluation of quercetin nanoparticle gel for osteoarthritis. Int J Appl Pharm 2019;11:54-9.

5. Seki A, Ikeda S, Kubo I, Karube I. Biosensors based on lightaddressable potentiometric sensors for urea, penicillin and glucose. Anal Chim Acta 1998;373:9-13.

6. Ozturk SS, Palsson BO. Chemical decomposition of glutamine in cell culture media: effect of media type, $\mathrm{pH}$, and serum concentration. Biotechnol Progr 1990;6:121-8.

7. Guilbault GG, Kauffman JM. Enzyme-based electrodes as analytical tools. Biotechnol Appl Biochem 1987;9:95-113.

8. Updike SJ, Hicks GP. The enzyme electrode. Nature 1967;214:986-8.

9. Fabre B, Simonet J. Electractive polymers containing crown ether or polyether ligands as cation-responsive materials. Coordination Chem Rev 1998;178-180:1211-50.

10. Clark LC, Lyons C. Electrode system for continuous monitoring in cardiovascular surgery. Ann NY Acad Sci 1962;102:29-45.

11. Li H, Xu B, Wang D, Zhou Y, Zhang $\mathrm{H}$, Xia W, et al. Immunosensor for trace penicillin g detection in milk based on supported bilayer lipid membrane modified with the gold nanoparticle. J Biotechnol 2015;203:97-103.

12. Liu J, Liang L, Li G, Han R, Chen K. H+ISFET-based biosensor for determination of penicillin G. Biosens Bioelectron 1998;13:1023-8.

13. Thust M, Schoning MJ, Muller Veggian M, Kordos P, Luth H. A long-term stable penicillin-sensitive potentiometric biosensor with enzyme immobilized by heterobifunctional cross-linking. Anal Chim Acta 1996;323:115-21.

14. Gonçalves LM, Callera WFA, Sotomayor MDPT, Bueno PR. Penicillinase-based amperometric biosensor for penicillin G. Electochem Commun 2014;38:131-3. 